Document downloaded from:

http://hdl.handle.net/10251/165795

This paper must be cited as:

Ballester Fernandez, A.; Pierola, A.; Solves Camallonga, C.; Parrilla Bernabé, E.; UrielMolto, J.; Zaimi-Tortajada, IIM.; Page Del Pozo, AF.... (2019). Study on controllable and uncontrollable factors affecting foot shape. Footwear Science. 11(Sup1):123-125. https://doi.org/10.1080/19424280.2019.1606113

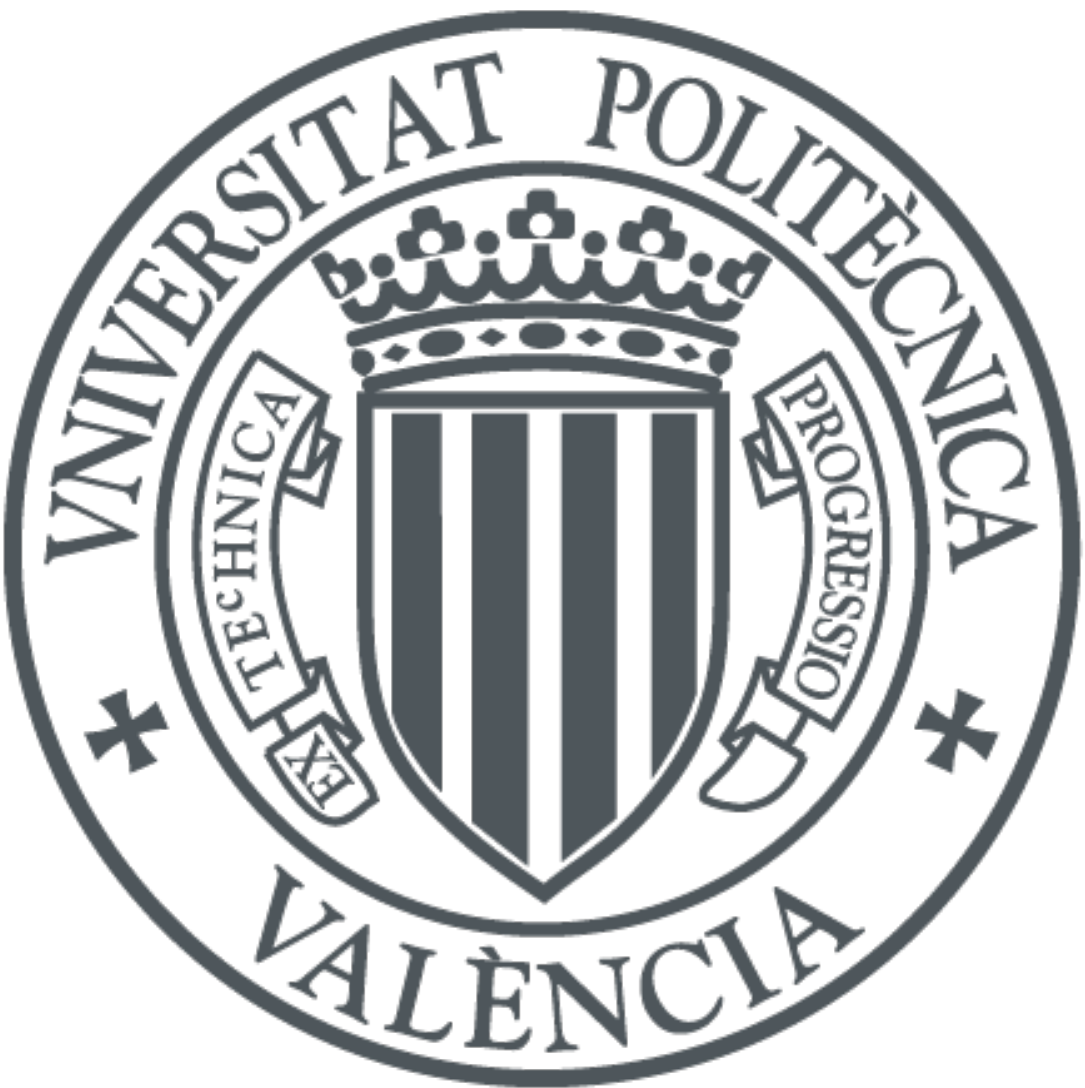

The final publication is available at

https://doi.org/10.1080/19424280.2019.1606113

Copyright Taylor \& Francis

Additional Information 


\title{
Study on controllable and uncontrollable factors affecting foot shape
}

\author{
Alfredo Ballester ${ }^{\mathrm{a}^{*}}$, Ana Piérola ${ }^{\mathrm{a}}$, Clara Solves ${ }^{\mathrm{a}}$, Eduardo Parrilla $^{\mathrm{a}}$, \\ Jordi Uriel $^{\mathrm{a}}$, Ibrahim Zaimi ${ }^{\mathrm{a}}$, Álvaro F. Page ${ }^{\mathrm{a}}$, Sandra Alemany ${ }^{\mathrm{a}}$ \\ anstituto de Biomecánica de Valencia, Universitat Politècnica de València, Spain
}

\section{Introduction}

Foot measurements can be used in health assessment and product design (e.g. footwear/orthotic personalization or size recommendation). Digital measurements have proven to be more reliable than traditional ones, even those obtained from data-driven $3 \mathrm{D}$ reconstruction technologies from few images gathered with a smartphone or lowcost booth (Ballester et al., 2017; Parrilla et al., 2015). These solutions can be made available to the mass public at homes, stores or medical offices. However, foot shape changes depending on load-bearing condition during digitization: standing (or half-weight bearing, HWB), and sitting (or non-weight bearing, NWB). Moreover, foot shape may also vary along the day (within-day) or between-days.

\section{Purpose of the study}

The purpose of this study was to analyze the effect of controllable (load-bearing condition) and uncontrollable factors (physiological changes within-day and between-days) on the main foot dimensions used in product design and clinical assessment.

\section{Methods}

16 healthy adult volunteers aged 24 to 63 participated in the study ( 8 females, 8 males). Each subject's right foot was digitized in three sessions. Session 1 took place in the morning. Session 2 took place the same day in the afternoon (6 hours later). Session 3 took place two days after session 1 . Feet were acquired and measured in standing posture (HWB) using DomeScan/IBV foot digitizer (Fig. 1). In session 2, they were also measured in sitting posture (NWB). For each session and condition, subjects' feet were digitized three times. Nine measurements were selected to be included in this paper due to their relevance: foot length (FL), toes girth (TG), ball girth (BG), ball width (BW), instep girth (IG), instep height (IH), ball height (BH), instep width (IW) and heel width (HW). A repeatedmeasures ANOVA was used to study each of the factors: load-bearing (fixed), within-day (fixed) and between-days (random).

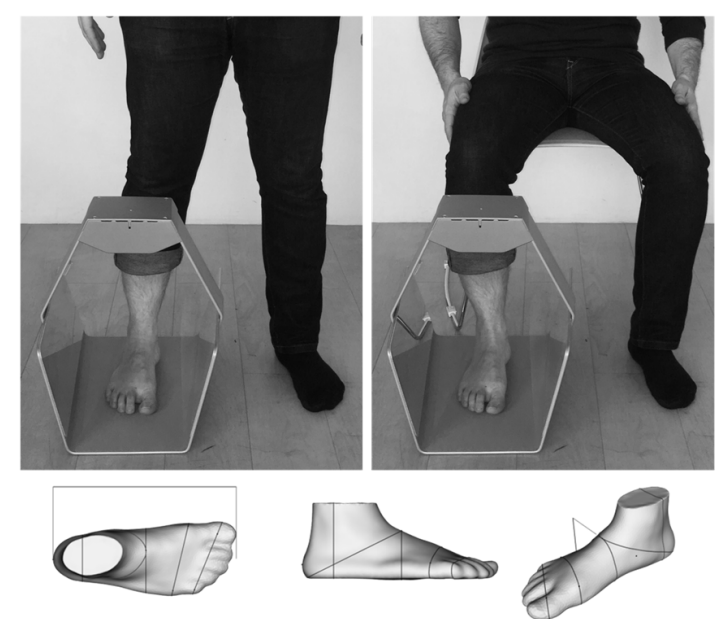

Figure 1. Foot acquisition and measurements 


\section{Results}

Variance estimates of between-days random errors were not significant compared to the residual error of repeated measurements within session. Table 1 summarizes the results of fixed-effect analyses.

Table 1. Fixed-effects (bias) in mm; Load-bearing $=$ HWB - NWB, Within-day $=$ afternoon - morning .

\begin{tabular}{|ccc|}
\hline Measurement & Load-bearing & Within-day \\
\hline FL & $4.9^{*}$ & 0.3 \\
TG & $4.3^{*}$ & -0.5 \\
BG & $1.8^{*}$ & 0.2 \\
BW & $1.7^{*}$ & -0.1 \\
IG & 0.3 & $0.9^{*}$ \\
IH & $-3.4^{*}$ & 0.1 \\
BH & $-2.1^{*}$ & 0.3 \\
IW & $3.2^{*}$ & $0.5^{*}$ \\
HW & $0.6^{*}$ & -0.1 \\
\hline
\end{tabular}

* Significant effects $(\mathrm{p}$-value $<0.05)$

\section{Discussion and conclusion}

We found that random errors of foot measurements taken between-days are similar to those of repeated measurements taken within the same session. Therefore, foot measurements taken at any moment can be a good reference, at least, in the short-term. Further research will be required to quantify long-term foot changes in adults.

We found no evidence of relevant $(>1 \%)$ foot measurement variations in healthy adults during the day. This supports previous studies in foot volume changes (Moholkar \& Fenelon, 2001).

Foot shape depends greatly on loading conditions. Under HWB condition, the foot widths, lengths and girths increase significantly (1-4\%), while heights decrease $(\sim 5 \%)$. Our results with European population are consistent with previous studies on Asian, American and African populations (Houston et al., 2006; Oladipo et al., 2009; Xiong et al., 2009). Thus, product design and clinical assessment processes using foot measurements must consider the loading conditions because the effects are larger than half a US footwear size (and nearly a full EU size).

\section{References}

Ballester, A., Piérola, A., Parrilla, E., Izquierdo, M., Uriel, J., Nácher, B., ... \& Alemany, S (2017). Fast, Portable and Low-Cost 3D Foot Digitizers: Validity and Reliability of Measurements. In Proc. of 3DBODY.TECH 2017, Montreal, Canada, 11-12 Oct. DOI: $10.15221 / 17.218$

Houston, V. L., Luo, G., Mason, C. P., Mussman, M., Garbarini, M., \& Beattie, A. C. (2006). Changes in Male Foot Shape and Size with Weightbearing. JAPMA, 96(4), 330-343. DOI: $10.7547 / 0960330$

Moholkar, K., \& Fenelon, G. (2001). Diurnal variations in volume of the foot and ankle. J Foot Ankle Surg, 40(5), 302-304. DOI: 10.1016/S1067-2516(01)80066-1

Oladipo, G., Bob-manuel, I., \& Ezenatein, G. (2009). Quantitative Comparison Of Foot Anthropometry Under Different Weight Bearing Conditions Amongst Nigerians. Internet J Biol Anthropol, 3(1), 1-7.

Parrilla, E., Ballester, A., Solves-Camallonga, C., Nácher, B., Antonio Puigcerver, S., Uriel, J., ... \& Alemany, S. (2015). Low-cost 3D foot scanner using a mobile app. Footwear Science, 7(sup1), S26-S28. DOI: 10.1080/19424280.2015.1038308

Xiong, S., Goonetilleke, R. S., Zhao, J., Li, W., \& Witana, C. P. (2009). Foot deformations under different load-bearing conditions and their relationships to stature and body weight. Anthropol Sci, 117(2), 77-88. DOI: 10.1537/ase.070915 